Journal of Computer Science 7 (8): 1224-1229, 2011

ISSN 1549-3636

(C) 2011 Science Publications

\title{
Implementing Rede Universitaria de Telemedicina Usability-the Brazilian Telemedicine University Network
}

\author{
Wilson Coury, Jose Luiz Ribeiro Filho, Luiz Ary Messina and Nelson Simoes \\ RNP-Rede Nacional de Ensino e Pesquisa-Brazilian National Research and Education Network, \\ Rua Lauro Muller 116 Sala 3902, Botafogo, \\ Rio de Janeiro, CEP: 22290-906, Brazil
}

\begin{abstract}
Problem statement: Remote and underserved regions in Brazil have a lack of specialized doctors for health assistance and education. Approach: The Brazilian Telehealth initiative enables videoconferencing, diagnosis and formative second opinion, continuous and permanent education and web conferencing, by linking university and teaching hospitals via RNP (Rede Nacional de Ensino e Pesquisa), Brazil's national research and education R and E network. Results: It operates two significant national projects: The Telemedicine University Network, RUTE (Rede Universitaria de TElemedicina www.rute.rnp.br, (Pesquisas e Ações em Saúde nos Institutos de Pesquisa do Ministério da Ciência e Tecnologia, N.1, 2010) and the National Telehealth Primary Care Program, Brazil Telehealth (www.telessaudebrasil.org.br); respectively from the Science and Technology Ministry MCT and Health Ministry MS. The municipal, state, national and international health institutions coordinate collaborative projects in research, innovation, development, management, education and assistance. Conclusion: At the moment 48 University and Teaching Hospitals operate their Telemedicine Nuclei and also a network of more than 200 institutions and their specialists participating in 40 Special Interest Groups, with ca. 2-3 sessions every day.
\end{abstract}

Key words: Telemedicine university network, video and web conferencing, telehealth centers or telemedicine nuclei, special interest groups, telehealth assistance, collaborative research

\section{INTRODUCTION}

RUTE's main objectives are:

- Connect the University and Teaching Hospitals to Brazil's national research and education $\mathrm{R}$ and $\mathrm{E}$ network through a 1 Gbps City Fast Ring for R and E Institutions

- Formally create a Telemedicine Nucleus in each Hospital

- Homologate a Videoconference Room

- Create initial infra-structure for Teleconsult and Telediagnosis

- Train Personnel for Video- and Webconference

- Create and stimulate participation in SIGs-Special Interest Groups

In its first phase, started January 2006, RUTE resources were available for 19 University Hospitals. Second phase, January 2007, included 38 institutions involving all University Hospitals from all Federal Universities in all federal states and 26 embrio institutions according to an agreement between RUTE/RNP and Telehealth Brazil. Third phase, started May 2009, selected 75 institutions, involving all public certified teaching Hospitals, federal health institutions and the federal indigenous health department. In January 2011, 28 projects from the third phase were approved and will receive their telehealth nuclei installation and equipment until December 2011.

The Ministry of Health integrates the initiative through the Telehealth Brazil, implanting initially in 9 states the remote Primary Care Program in the University Hospitals attending 100 Municipalities in each state, yielding 900 operational at the moment.

Advanced network infrastructure: RUTE implements communication infrastructure in university and teaching hospitals in the largest 53 cities in Brazil, enabling the establishment of telemedicine and telehealth centers with investments on equipment, connectivity and ambience preparation. The goal of the project is allowing all participating hospitals to use the National Network for Education and Research in order to operate applications on telemedicine and telehealth, including video and webconference for exchanging information, talks, continuing education, formative second opinion and teleconsultation, creating a base for collaboration among hospitals and training them for remote collaboration.

Corresponding Author: L.A.Messina, RNP-Rede Nacional de Ensino e Pesquisa, Rua Lauro Muller 116 sala 3902, Botafogo, Rio de Janeiro, CEP: 22290-906, Brazil 


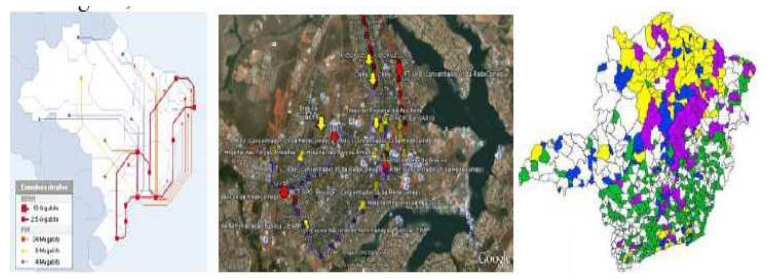

Fig. 1:RNP national backbone; Brasília Redecomep R and E Network; 600 municipalities covered by the Minas Telehealth in the state of Minas Gerais

The $\mathrm{R}$ and E Metropolitan Community Networks (Redecomep) implements communication infrastructure in the 27 brazilian capital cities through its Points of Presence (PoPs-www.redecomep.rnp.br ). It expands now to 10 more cities. The goal of the project is to connect all main public universities and research centers in the country, with optical fiber managed by a local consortia made up of these institutions and RNP.

However, the participation of state and municipal governments on $\mathrm{R}$ and $\mathrm{E}$ networks is opening up new possibilities including public schools and health care centers.

These metropolitan networks are being installed and full operation is expected by 2010 in the capital cities (Fig. 1). Currently, sixteen capital cities operate the Redecomeps with 290 institutions.

Metropolitan networks are connected nationally by the National $\mathrm{R}$ and $\mathrm{E}$ Network backbone with current Gigabit connection capability in ten PoPs (10Gbps for Rio de Janeiro, São Paulo, Brasília and Belo Horizonte and 2,5 Gbps for Porto Alegre, Florianópolis, Curitiba, Fortaleza, Recife and Salvador) - http://www.rnp.br/backbone/index.php . All $10 \mathrm{~GB}$ is coming.

\section{MATERIALS AND METHODS}

The following procedures are implemented for setting the structure of the Telemedicine University Network operational methodology:

- Establishment of the organizational and technological infrastructure: national coordination, advisory committee made up of telemedicine experts of the country's best teaching and research institutions, interest groups on specific health areas and also executive, maintenance, communication and operational teams of the national and local telemedicine and telehealth network

- The Advisory Committee (CA-RUTE) recommends the procedures for the innovative use of the Telemedicine University Network

- Each member institution establishes the telemedicine and telehealth Nucleus/Center with a physical area and a dedicated team
- Member institutions establish SIGs to promote and develop collaboration activities on telemedicine and telehealth specific topics

- Organize workshops to encourage everyone's understanding of the collaboration work for the national integration on teaching, research and the improvement of health care service for the population.

Implementing network phase I: Implementation Phase I is concluded. All 19 University Hospitals (HUs) and their formally created Telehealth Centers are fully connected and operational. The institutions received equipment and implementing services according to each Project and Workplan. All connected in the NREN communication infraestructure from RNP, participate regularly in video- and webconferecing sessions. The institutions involved in this phase are: UFPR, Unifesp, Pazzanese, Unicamp, Ufes, UFBA, Ufal, UFPE, UFPB, UFC, UFMA, Ufam, FioCruz, HC-FMUSP, HU-USP, ISCMPA, Uerj, UFMG, UFSC, almost all, hospitals from federal and state universities.

Implementing network phase II: 29 out of 38 members of phase II and their formally created Telehealth Centers are fully connected and operational. The others have already received all equipment and should be fully connected and operational in 2010. The institutions involved in this phase are all university hospitals from federal universities and 5 health faculties from federal universities without yet university hospitals, in demanding regions in the so-called Legal Amazonia in the states of Amapa, Roraima, Acre, Rondonia and Tocatins.

Implementing network phase III: Phase III started May 2009 incorporated 75 new institutions, 60 Teaching Hospitals and 15 federal health institutions. 50 institutions have already submitted their projects, goals and list of equipment to constitute the Nuclei. 28 projects have been approved and these institutions have signed the cooperation terms with RNP in 2010 for receiving equipment and connection in 2011.

Implementing usability: To guarantee high network efficiency, the advisory commitee focused on answering the following questions.

Which services are essential to run a Telemedicine University Network and create a virtual health community:

- Enable communication infrastructure

- Guarantee integration and service quality

- Stimulate collaborative research, interinstitutional formal courses and health assistance

- Involve main actors: government, university, enterprise

- Indicators to evaluate services 


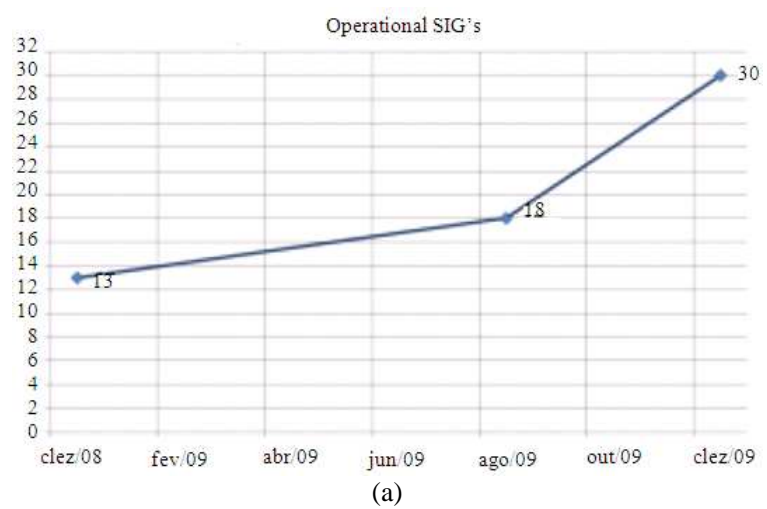

(a)

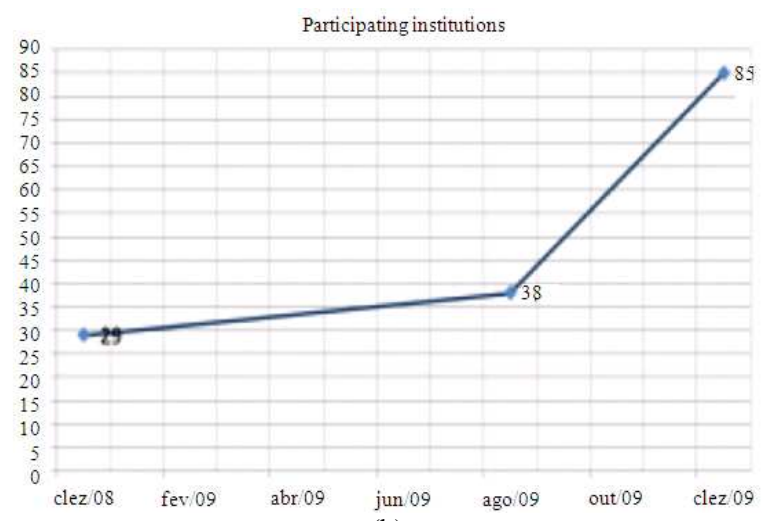

(b)

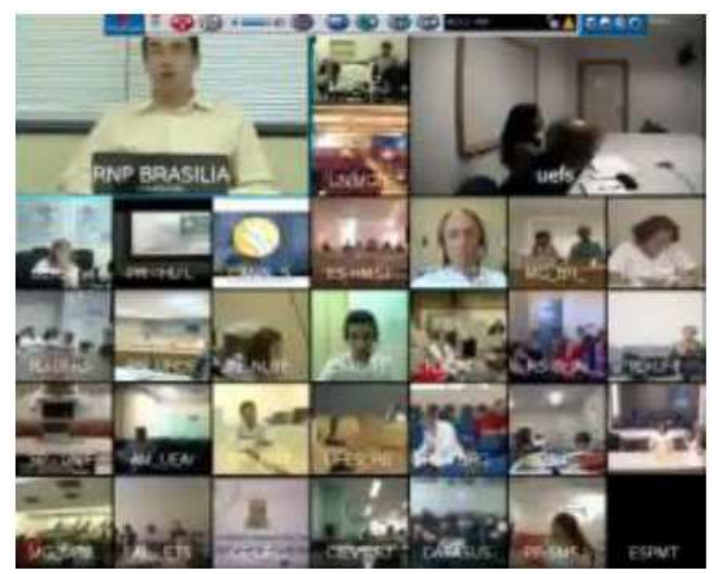

(c)

Fig. 2: The increasing number of SIGs in operation, RUTE member institutions participating and a videoconference with 37 Nuclei in all 27 brazilian states on Dengue prevention

Stimulate and coordinate national and international special interest groups.

Which other factors guarantee demand and sustainability:
- Health professionals are highly creative building applications and developing new eHealth ICTs

- The majority of health professionals will be affected by eHealth ICTs in research, education, diagnosis, management and assistance

- Introduction of health informatics, telemedicine, telehealth, bio-and nanotechnology in health universities will strengthen the national health system

- SIGs are created and coordinated by members RUTE; health professionals build the annual videoor webconferences sharing specific themes. The sessions per month, week, debate cicle, defined by the group, may be focused on education, research and assistance, by formative second opinion

There are 40 SIGs today with more than 500 Video- and webconferencing sessions in 2009 and 2010: Cardiology, Pediatric Cardiology, Surgery and Traumatology, AIDS, Nursing in Intensive Care and High Complexity, ENT-Ear Nose and Throat, Management Teaching and University Hospitals, Rural Internship, Neuroradiology, Dentistry - Oral Diagnosis, ophthalmology, Onco-Gynecology, Standards for Telemedicine and Health Informatics, Telehealth Research, Development and Innovation, Quality and Safety in Hospitals Sentinel Network, Abdominal Radiology, Radiology and Diagnostic Imaging in Pediatrics, Radiology and Diagnostic Imaging in Chest, Health Children and Adolescents, Nursing Services, Technical Operations in Telemedicine Centers, Telecoloproctologia, teledermatology, Telenursing, telepsychiatry, Tele Network Human Milk Bank, Clinical Toxicology, Urology, Pediatric Urology, Endometriosis.

The number of institutions participating in the periodic sessions have surpassed 70 and 400 persons (Fig. 2), including Rute members and other institutions. Implementing phase III, the number of participating institutions will enlarge as also the diversity of specific themes and operations, as already suggested by the newcomers according to their projects. Following phase III projects intention, a total of 50 SIGs is expected in 2011.

An entrepreneurial integrated ministerial approach is also being articulated in order to establish a common strategy at national level on health focused relevance, guidance and sustainability aspects, taking into account entrepreneurial plans and partnership with the RUTE members, enhancing market oriented $\mathrm{R}$ and $\mathrm{D}$ Nuclei activities. 


\section{RESULTS}

RUTE member projects integrate at the moment 158 health institutions. It connects today 48 Nuclei fully operational.

RUTE performs daily routine $\mathrm{VC}$ or Webconference sessions, each specialty at least once a month, on pediatrics radiology, oncology, urology, children and adolescent health, dermatology, cardiology, oftalmology. There are 30 SIGs operational and at least 12 more in 2010. A total of ca. 250 sessions were held in SIGs in 2009 (Fig. 3).

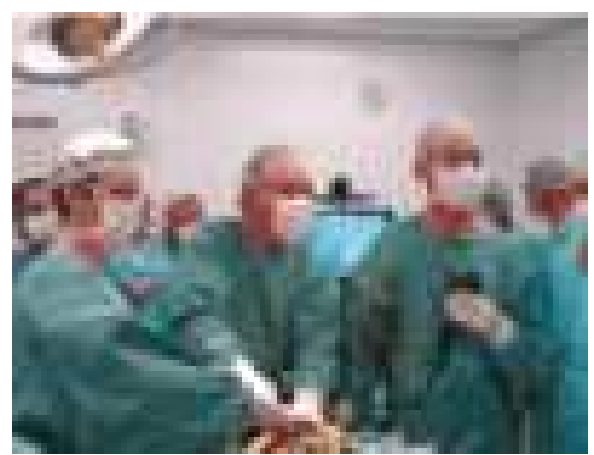

(a)

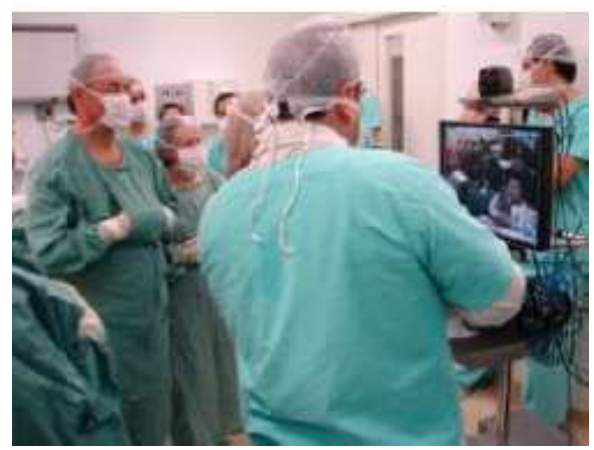

(b)

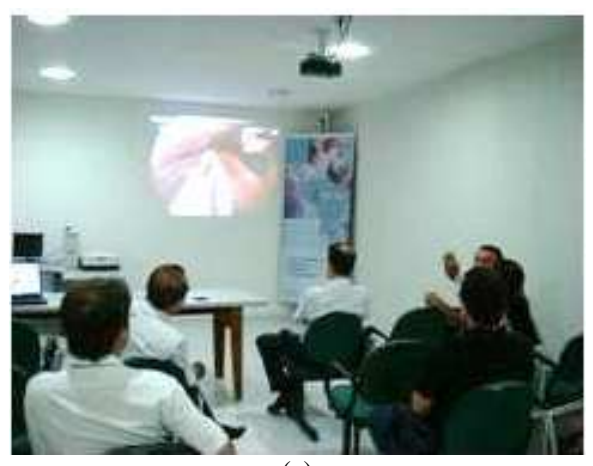

(c)

Fig. 3: A NOTES transvaginal colecistectomy surgery performed and transmited at ISCMPA by Prof.Dr.Luiz Alberto de Carli on Sept 30th 2008
There has been a $137 \%$ increase in the participation of institutions in the groups in 2009, from 89 to 211 institutions, including invited institutions. In some groups up to 400 people participated from remote areas in specific sessions on intensive nursing.

Telehealth Brazil shows already results implemented in 9 states, 9 RUTE Nuclei, assisting 2700 teams of the Health Family Program PSF in 900 municipalities, covering 11.000 .000 inhabitants.

In addition, as it happens with the added value of the program Tele Minas Saúde (Minas Telehealth Fig. 1) financed by the State Government Health Department and coordinated by Prof. Dr. Beatriz Alkmin, ECG formative second opinion is guaranteed for each of the 600 municipalities, on duty service 12 hours, 7 days per week shared with the following National University Hospitals: UFMG, UFU, UFTM, UFJF and Unimontes, yelding more than 900 consults and formative second opinion per day.

International collaboration: The encouragement for the continuous development in this area comes from the following mechanisms:

- Cooperation signed between Internet2 and RNP in Health Sciences

- Program for Innovative Continuing Medical Education in Dermatology, with the American Academy of Dermatology and the University of Miami

- Laboratory of Excellence and Innovation in Telehealth-Latin America and Europe, in Belo Horizonte

- Establishment of a SICOT Tele-Education Center on orthopedics and trauma in Rio

- Regional Protocols for Public Policies on Telehealth in Latin America, an IADB project, started October 2009. The Health Ministries from the following countries signed the letter of compromise: Brazil, Colombia, Ecuador, El Salvador, Mexico, Uruguay, RNP and RedClara (http://www.medicina.ufmg.br/teste_telesaude/inde x.html) (Oviedo, 2010)

RUTE is also been used as an innovation example in scientific collaboration, enabling the development of nuclei in the university hospitals and researchers integration in all regions in Brazil. It is being considered relevant and innovative by the University Corporation for Advanced Internet Development (UCAID-Internet2) and Terena (Trans-European Research and Education Networking Association), as stated by the Internet 2 Health Sciences coordinator Michael McGill in the 1st Terena Day Networking 
Conference 2009 in Malaga, Spain: "Real-life impacts of networking Technologies - Telehealth structures are less advanced in the USA, according to Michael McGill, who is responsible for health sciences for Internet2"(http://tnc2009.terena.org/media/news.php\# n2439).

IADB, the Interamerican Development Bank appoved in 2008 the project Telehealth Public Policies in Latin American. The contract has been signed in October 30th and launched in December 9th 2009 in Belo Horizonte, Brazil, during the II Workshop of the Laboratory of Excelence and Innovation in Telehealth Latin America and the IV Brazilian Congress on Telemedicine and Telehealth, with more than 700 participants, 30 of them representing 20 countries. The main components of the project are:

- Regional Standards for transmission and infraestructure

- Strategy for the promotion, prevention and assistance through telehealth

- Regional guide for telehealth managing

- Strategy for a Latin America Telehealth University Network

- Telehealth training and certification

The project period amounts 36 months. Other countries will be able to participate and contribute in the 3 project workshops, also because other resources/funds for their participation is being articulated with CEPAL.

\section{DISCUSSION}

There is neither more question nor discussion if ICTs should be used for benefit in any human, economical or social field, but how effectively this application must be addressed. The world and specifically the health professionals are starting to experience the results that can be achieved by developing new models and procedures for assistance, education, collaborative research and management, using telehealth tools. There are no questions that these are extensively applicable to countries with vast remote regions where there are no available specialists, or risk areas, or devastated areas, or unequally distributed health professionals formed areas. Therefore, it definitely applies to all countries except small and well developed countries.

The question here is: How best a model fits its application and demand. The Telehealth national model been applied at the moment in Brazil takes into account three major aspects: the public health scenario, focused on primary care and the distributed diseases demand, the availability of specialists in university and teaching hospitals and the integration, coordination and financing procedures coming from the national Education, Science and Technology and the Health Ministry.

\section{CONCLUSION}

Previous research projects at the brazilian universities showing remote assistance, education and collaborative research, also stimulated by the @lis results from the European Union, including RedClara for interconnecting Latin America NRENs, encouraged government actions and public investments on communication infrastructure, telemedicine and telehealth.

From the 57 initial University and Teaching Hospitals, 48 are fully connected and running Telehealth Nuclei with a range of 6 to 50 staff persons. More than 630 institutions participate in the 40 Special Interest Groups SIGs discussing important cases and procedures. Each SIG has at least one presentation a month; some have 2 or 4 . So that, every day there are ca. 2 to 3 videoconference sessions, varying from 6 to 90 participating persons.

With the participation and financial contribution coming from some State Health Department, Minas Gerais reaches 600 out of 852 Municipalities, contributing to 1000 second opinions a day only in electrocardiogram and Santa Catarina reaches 235 Municipalities. Besides, regarding alone the national contribution coming from the Telehealth Brazil Program, plus 1200 Municipalities are receiving in their assistance centers telehealth support to the doctors and patients. Estimates calculate around $12 \%$ savings in municipality costs.

Telehealth Brazil is also enabling a coordinated and integrated expansion to all 27 federal states through the Ordinance No 402 (Oviedo, 2010).

The main reasons for the continuity and success of the network in Brazil are: federal initiative and coordination, state initiatives, integration and synchronization between the two main complementary projects and members: RUTE (Ministry of Science and Technology) and Telehealth Brazil (Ministry of Health). A newly 2010 created complementary telehealth program from the Ministry of Health is mainly in charge of continuous education in primary care: UNASUS Universidade Aberta do SUS - Open University for Health Universalization http://portal.universidadeabertadosus.org.br/ . 


\section{ACKOWLEDGMENT}

To all RUTE members, the RUTE Committee, the National Telehealth Primary Care Program, the Brazilian National Education and Research Network RNP, Brazilian University and Teaching Hospitals Association Abrahue, Ministry of Education, Ministry of Health, Ministry of Science and Technology and the Brazilian National Studies and Projects Financing Agency FINEP.

\section{REFERENCES}

Oviedo, A.F.E., 2010. Salud electrónica en América Latina y el Caribe: avances y desafíos. División de Desarrollo Social. http://www.eclac.org/cgibin/getProd.asp?xml=/publicaciones/xml/5/41825/ P41825.xml and xsl=/dds/tpl/p9f.xsl and base $=/ \mathrm{dds} /$ tpl/top-bottom.xsl

Pesquisas e Ações em Saúde nos Institutos de Pesquisa do Ministério da Ciência e Tecnologia, N.1, 2010. Brasília: Ministério da Ciência e Tecnologia, Subsecretaria de Coordenação das Unidades de Pesquisa, 2010, pp:. 233-259. ISBN: 978-8588063-06-8 